\title{
Generator Digital Regulators Distributed Generation Plants
}

\author{
Yuri N. Bulatov \\ Bratsk State University \\ Bratsk, Russia \\ bulatovyura@yandex.ru
}

\author{
Andrey V. Kryukov \\ Irkutsk State Transport University \\ Irkutsk National Research \\ Technical University \\ Irkutsk, Russia \\ and_kryukov@mail.ru
}

\author{
Nguyen Van Huan \\ Irkutsk National Research \\ Technical University \\ Irkutsk, Russia \\ huanco.k7a@gmail.com
}

\begin{abstract}
The article provides results of power supply systems modes' computer-based research conducted with distributed generation (DG) plants equipped with digital automatic voltage regulator (AVR) and automatic speed governor (ASG). Lookahead algorithms were used to enhance control quality. Analysis of digital regulators effect on transient processes indices for disturbances of power supply system operating mode. The results of computer-based modeling performed in MATLAB system indicated that the use of look-ahead algorithm al-lowed to significantly improve controllers damper properties and reduce the object's persistence during DG plants transition to island operation, and when powerful asynchronous motors are started.
\end{abstract}

Keywords-distributed regeneration, digital automatic voltage regulator, digital automatic speed governor, lookahead algorithm, computer-based modeling

\section{INTRODUCTION}

A broad-scale use of digital technologies and devices in power generation industry allows construction of active-adaptive networks controlled by intelligent systems [1-16]. That is why, the development of digital distributed generation (DG) plants acquire special urgency. Digitization of power generation industry combined with intelligent systems, when correctly used, would allow enhancing control efficiency, durability and reliability of power supply systems.

To ensure DG plants steady operation based on synchronous generators, and to damp oscillations that occur, automatic voltage regulator (AVR) and automatic speed governor (ASG) are used. Microprocessor AVR and ASG would allow implementation of necessary interfaces to ensure communication with other digital devices and ensure efficient intellectual systems control. However, in order to achieve control optimization, the issue of these regulators tuning shall be resolved which requires labor consuming calculations for a significant number of interrelated parameters. The use of lookahead algorithms in microprocessor AVR and ASG allows ensuring the necessary system's damper properties, while having to tune one parameter only the look-ahead period [17-18]. The use of auto lookahead ASG [19] and microprocessors allows defining this parameter automatically in the real time mode, thus adapting DG plant to constantly varying power supply systems (PSS) operating modes.
The article provides description of AVR lookahead models building and auto look-ahead ASG of DG plant synchronous generator based on discrete activation functions while using $\mathrm{z}$-transformation apparatus. The study of digital regulators influence with look-ahead algorithms on the DG plants control quality when changing the operating mode of the power supply system. The following commutations in PSS were viewed as disturbances: shut down of centralized power supply (DG plant transition to island operation); starting asynchronous motors during DG plant operation in island operation mode.

\section{OPERATING PRINCIPLE OF AUTO LOOK-AHEAD SPEED GOVERNOR OF SYNCHRONOUS GENERATOR}

DG plant synchronous generator with auto lookahead regulator (Fig. 1) speed control can be implemented in digital regulator with proportionalintegral-differential (PID) law of control and series connected forecasting link [18].

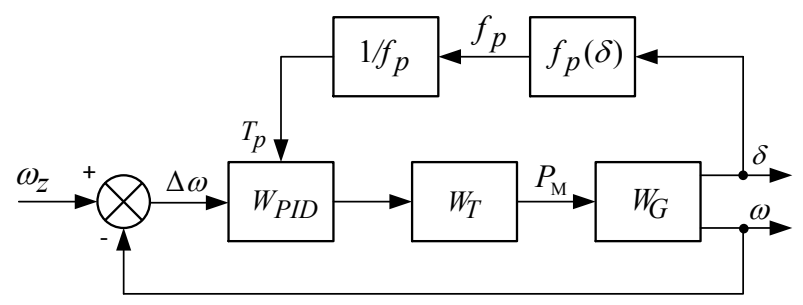

Fig. 1. Structural diagram of auto look-ahead regulator-equipped generator speed control system: $W_{G}-$ generator activation function; $W_{T}$ - turbine activation function; $W_{P I D}-$ activation function of PID regulator equipped with forecasting link.

A simple linear forecast in ASG can be implemented by speeds of generator rotor rotation speed - current $\omega(t)$ and previous $\omega(t-\Delta t)$; in this case, activation function of the forecasting link is determined as follows [17]:

$$
W_{\text {for }}(s)=T_{p} s+1
$$

where $T_{p}$ - the time constant of linear forecasting link (look-ahead period); $s$-Laplasian operator.

The use of auto look-ahead ASG allows to automatically tune the control system by changing one parameter only - the time constant of the forecasting link. This parameter, as it was noted in [17-19], depends on frequency of optimally tuned initial closed 
system's own oscillations. When using DG plants based on synchronous generators in PSS, the calculation of units own oscillations can be performed using formula [20]:

$$
f_{p}=\frac{\sqrt{\frac{E_{q} \cdot U_{g}}{X_{d}} \cdot \cos \delta \cdot \frac{\omega_{0}}{T_{j e}}}}{2 \pi},
$$

where $f_{p}$ - frequency of synchronous generator rotor own oscillations when module, voltage vector angle on its buses - partial frequency which is the generator parameter featuring its sluggishness and rigidity of its connection with PSS [20]; $\omega_{0}-$ rated angular frequency of generator rotor revolution, $\mathrm{rad} / \mathrm{s} ; T_{j e}-$ equivalent constant of the unit mechanical inertia, $s$; $X_{d}$ - inductive impedance of the generator along the longitudinal axis, rel.units; $U_{g}-$ generator rated voltage, rel.units; $\delta$ - angle between voltage and generator EMF $E_{q}$, which depends on load mode, el. deg.

Period of DG plants units own oscillations which in this case is a forecast period, can be determined using the expression $T_{p}=1 / f_{p}$. It is evident from the expression (2) that synchronous generator rotor oscillations, and consequently, the time constant of the forecasting link, depends on $\delta$ angle. Taking into account this circumstance and that contemporary highperformance generators excitation thyristor systems allow to maintain generator voltage in normal operating modes virtually unchanged, it is expedient to calculate and change the constant of forecasting time while varying PSS operating mode. The represented look-ahead speed regulator does not require coefficients optimization of PID regulator tuning and determining the time constant of the forecasting link. One has to know DG plant unit parameters only, that are used in the expression (2).

III. DESCRIPTION COMPUTER MODEL OF POWER SUPPLY SYSTEM UNDER CONSIDERATION AND MODELS OF SYNCHRONOUS GENERATOR DIGITAL REGULATORS

Modeling was carried out for a big industrial enterprise PSS whose structural diagram is represented in Fig. 2. PSS power supply was performed from an interconnected power system (IPS) using 110/10 kV transformer. The power grid was characterized by a significant branching of collectors groups power supply via overhead power lines and $10 \mathrm{kV}$ cable lines with voltage reduction to $0.4 \mathrm{kV}$ in workshop transformer substations. Turbo generator plant (TGP) was used as DG plant. An equivalent static activeinductive loading was taken into account for $10 \mathrm{kV}$ and $0.4 \mathrm{kV}\left(\dot{S}_{1}, \dot{S}_{2}\right)$ during PSS model development.
The PSS under study model was created in MATLAB environment while using Simulink and SimPowerSystems simulation modeling packages. TGP steam turbine was modeled using the activation function $\frac{1}{0.2 s+1}$. A synchronous machine model with damper winding was used for TGP generator, the model being a component of the SimPowerSystems package. The excitation system was modeled by firstorder device with $k_{f}$ coefficient, time constant $T_{f}$ and voltage limiting unit. In addition, amplifier with $k_{a}$ coefficient, time constant $T_{a}$, were taken into account in the model. The following numerical parameter values were accepted: $k_{a}=1 ; T_{a}=0.001 \mathrm{~s} ; k_{f}=1 ; T_{f}=$ 0.025 s. Digital prognostic AVR (with look-ahead algorithm) was used as excitation regulator whose model is built based on discrete activation functions while using z-transformation (Fig. 3).

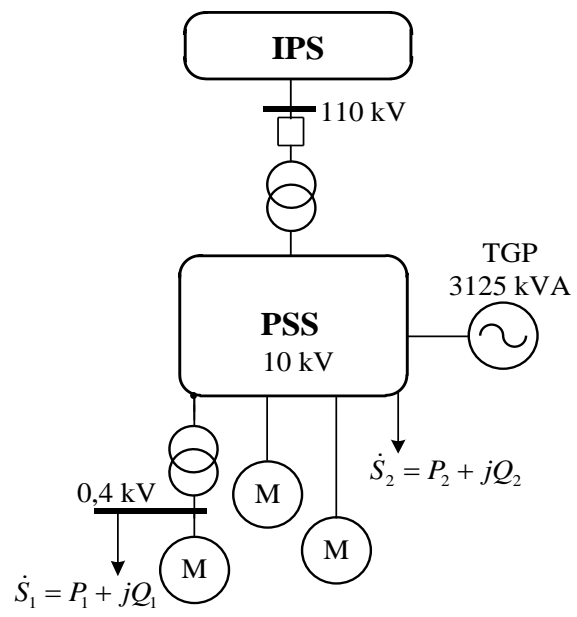

Fig. 2. Diagram of the PSS under study.

Time constant of forecasting link for AVR was accepted as equal to $0.01 \mathrm{~s}$. Fig. 4 provides structural diagram of ASG model with the forecasting link. The following parameters were set for turbo generator: $X_{d}=2.34$ rel.units, $E_{q}=1.25$ rel.units, $U_{g}$ $=1$ rel.units, $T_{j e}=5.13 \mathrm{~s}$; in this case, function $f_{p}(\delta)$ acquired the following form: $f_{p}(\delta)=0.911 \cdot \sqrt{\cos \delta}$.

\section{MODELING RESULTS}

AVR and ASG tuning coefficients were determined with view to regulators interplay by harmonized setting method [12, 16]. The following modes were analyzed to study digital look-ahead regulators influence upon DG generator speed and voltage control:

- centralized power supply shut off (DG plant transition to island operation);

- starting asynchronous motors when TGP is in island operation. 


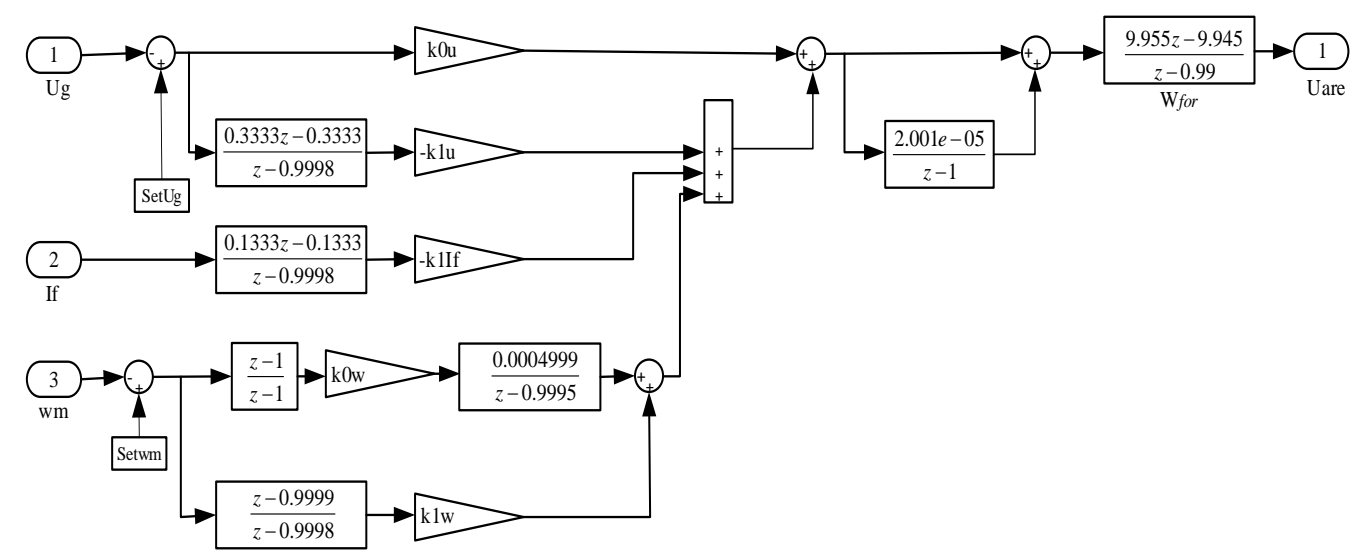

Fig. 3. Structural diagram of digital prognostic AVR model is as follows: $U_{g}$ - generator current voltage value; Set $U_{g}$ - generator voltage preset value; $I_{f}$ - generator excitation current; $\omega_{m}$ - current value of generator rotor speed; ${\text { Set } \omega_{m}}_{-}$-generator rotor speed preset value; $k_{0 u}, k_{1 u}, k_{1 f f}, k_{0 \omega}, k_{1 \omega}-\mathrm{AVR}$ tuning coefficients; $W_{f o r}$ - discrete activation function of electronic amplifier and the forecasting link with time constant $T_{p}=0.01 \mathrm{~s}$.

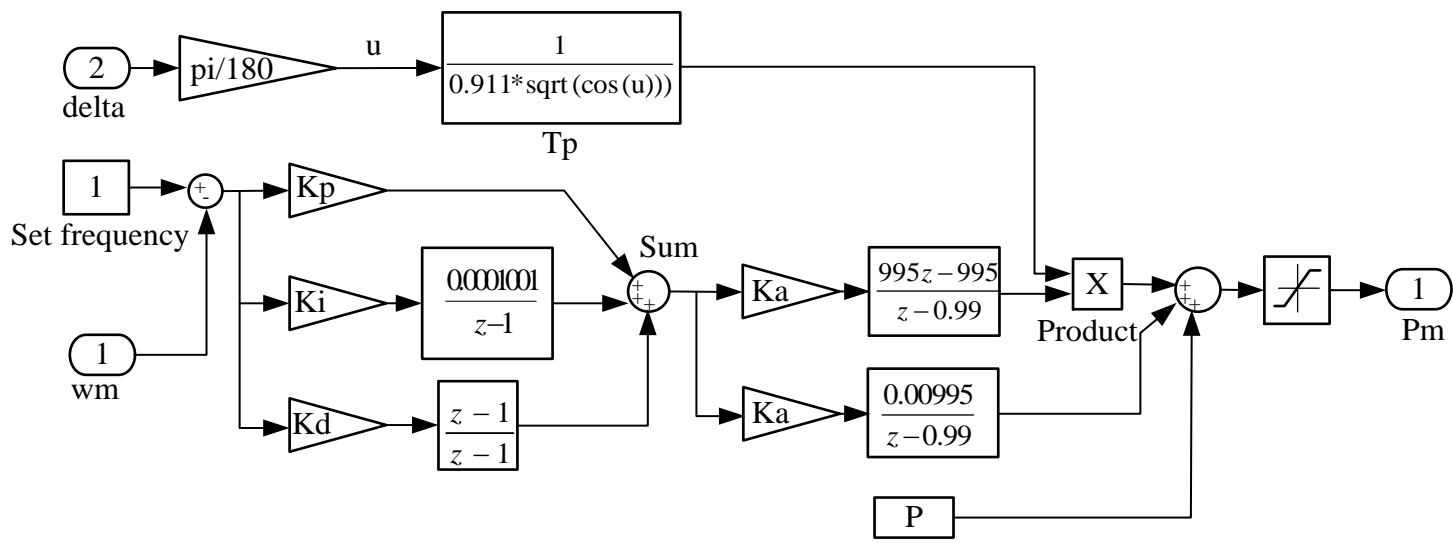

Fig. 4. Structural diagram of digital auto look-ahead ASG model is as follows: Kp, Ki, Kd - ASG tuning coefficients; Ka - amplifier gain; $\mathrm{P}$ - initial turbine loading.

Modeling results indicated that using look-ahead AVR and auto look-ahead ASG when DG plant is transferred into island operation due to centralized power supply shut down, allows to significantly reduce object persistence and to reduce control time for turbine mechanical power as compared with typical AVR and ASG. Apart from this, turbine mechanical power over control value and generator rotor speed is virtually reduced to zero (Fig. 5 a, b).

The use of look-ahead algorithms in AVR also allowed to more accurately maintain DG plant voltage during its transition to island operation (Fig. 6.).

Results of asynchronous motors start modeling during TGP island operation, allowed to infer that using look-ahead AVR and auto look-ahead ASG makes it possible to considerably improve damper properties of regulators and reduce persistence. As a result, transition process time is reduced for turbine mechanical power, rotor speed and generator voltage. Relevant oscillograms confirming these inferences are provided in Fig. 7 and 8.

\section{CONCLUSION}

The computer modeling results allowed to make the following conclusions:

1. The developed models of digital look-ahead voltage and speed regulators for distributed generation plants allow to improve quality of turbine mechanical power control, rotor speed and generator voltage. When DG plant is transferred into island operation due to centralized power supply shut down, the use of look-ahead regulators allows to significantly reduce object persistence and reduce control time in comparison with typical AVR and ASG. Look-ahead ASG reduces the value of turbine mechanical power and DG plant generator rotor speed virtually to zero when transition to island mode is considered.

2. When AVR and ASG are used, regulators damper properties are improved significantly and object persistence is reduced when asynchronous motors are started and TGP is in island operation. 
Turbine mechanical power, rel. units

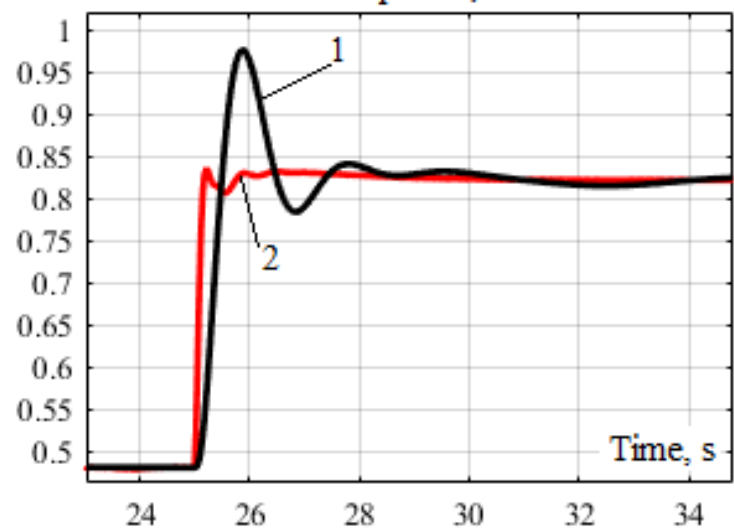

a)

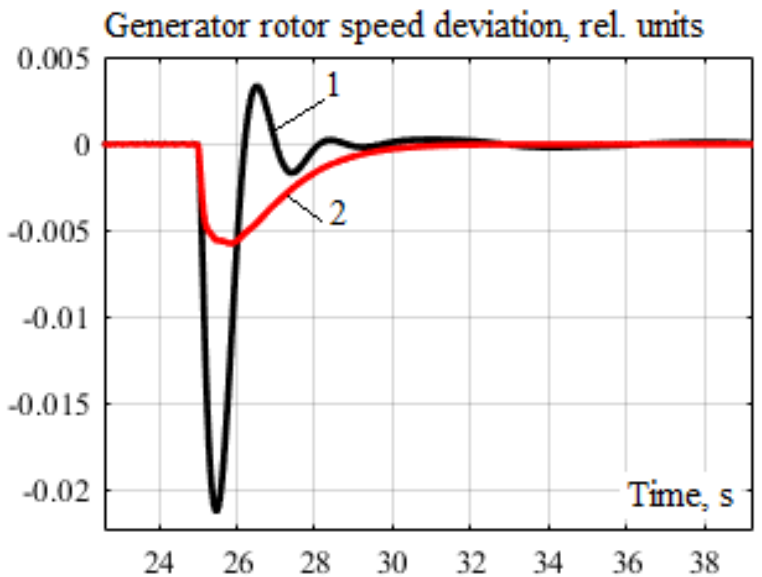

b)

Fig. 5. Oscillograms of turbine (a) mechanical power change and deviation of generator rotor speed (b) when centralized power supply is shut off: 1 - digital AVR and ASG were used without forecasting links; 2 - digital look-ahead AVR and auto look-ahead ASG were used.

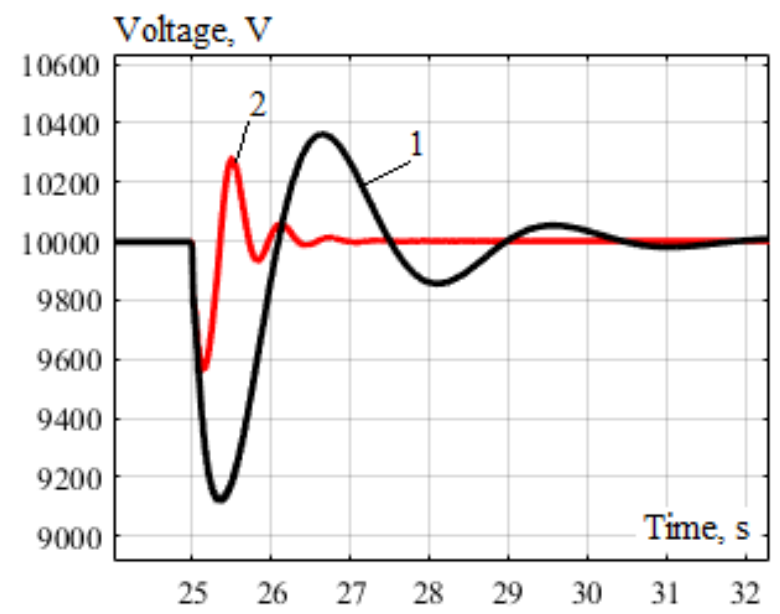

Fig. 6. Oscillograms of generator voltage change for centralized power supply shut off: 1 - digital AVR and ASG were used without forecasting links; 2 - digital look-ahead AVR and auto look-ahead ASG were used.

Turbine mechanical power, rel. units

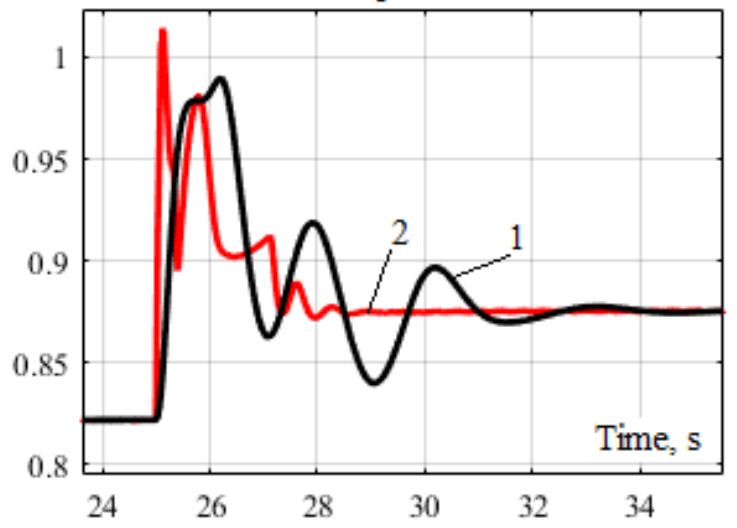

a)

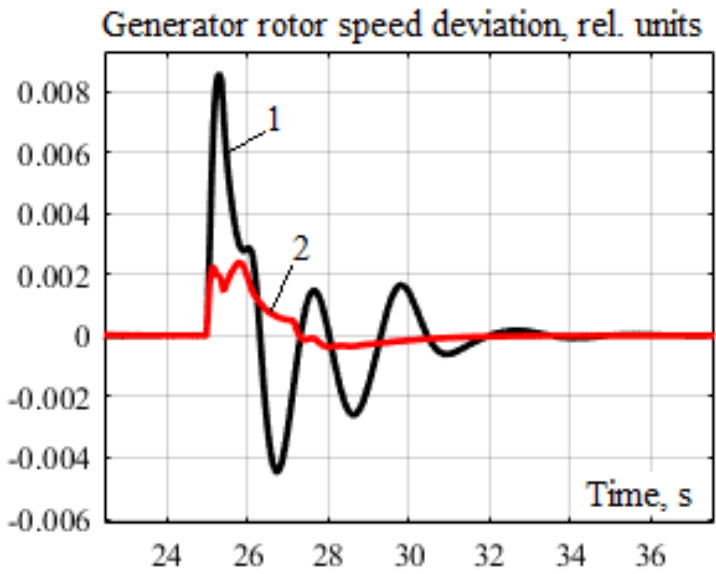

b)

Fig. 7. Oscillograms of turbine (a) mechanical power change and deviation of generator rotor speed (b) when asynchronous motors are connected to TGP: 1 - digital AVR and ASG were used without forecasting links; 2 - digital look-ahead AVR and auto look-ahead ASG were used. 


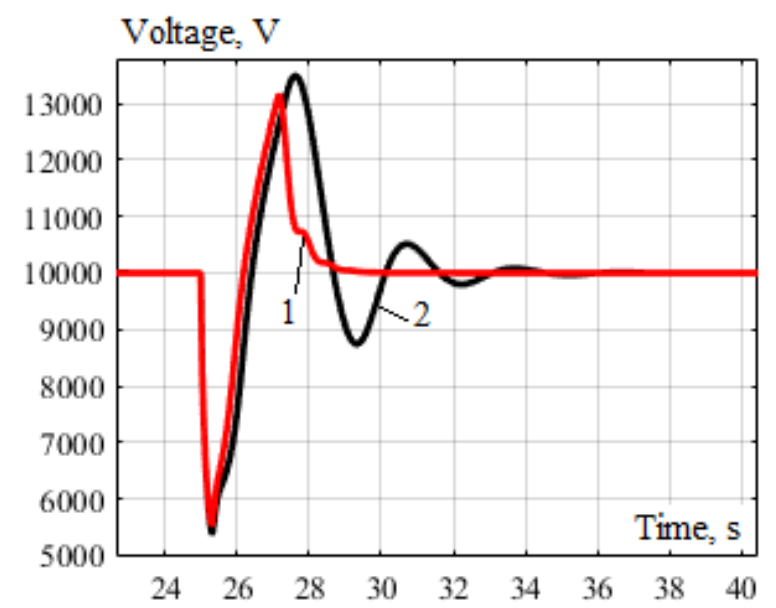

Fig. 8. Oscillograms of generator voltage change when asynchronous motors are connected to TGP: 1 - digital AVR and ASG were used without forecasting links; 2 - digital look-ahead AVR and auto look-ahead ASG were used.

3. The proposed digital regulators can be used for enhancing stability, adaptability and durability of power distributed generation plants operating in the power supply system. Auto look-ahead speed regulator of synchronous generator can be recommended when it is necessary to promptly introduce distributed generation plants into operation.

\section{REFERENCES}

[1] Yu.I. Morzhin, Yu.G. Shakaryan, Yu.N. Kucherov et al., "Smart Grid Concept for Unified National Electrical Network of Russia", Preprints of proceedings of IEEE PES Innovative Smart Grid Technologies Europe 2011. (GB: IEEE, The University of Manchester, 2011). Panel session 5D, pp. 1-5.

[2] Torriti J. Demand, "Side Management for the European Supergrid: Occupancy variances of European single-person households", Energy Policy. 2012, vol. 44, pp. 199-206.

[3] F.N. Mohsen, M.S. Amin, H. Hashim, "Application of smart power grid in developing countries", IEEE 7th International Power Engineering and Optimization Conference (PEOCO), 2013. DOI:10.1109/PEOCO.2013.6564586.

[4] Bernd M. Buchholz, Zbigniew A. Styczynski, Smart Grids Fundamentals and Technologies in Electricity Networks (Springer-Verlag Berlin Heidelberg, 2014). 396 p.

[5] Wang J., Huang A.Q., Sung W., Liu Y., Baliga B.J., "Smart Grid Technologies", IEEE Industrial Electronics Magazine. 2009. vol. 3. No 2. pp. 16-23.

[6] Magdi S. Mahmoud, Fouad M. AL-Sunni, Control and Optimization of Distributed Generation Systems (Cham: Springer International Publishing : Imprint: Springer, 2015). $578 \mathrm{p}$.

[7] Martínez Ceseña E. A., Capuder T., Mancarella P., "Flexible distributed multienergy generation system expansion planning under uncertainty", IEEE Transaction on Smart Grid. 2016, vol. 7, pp. 348-357.

[8] P. Lombardi, Z.A. Styczynski, T. Sokolnikova, K. Suslov, "Use of energy storage in Isolated Micro Grids", Power Systems Computation Conference (PSCC) 2014, (IEEE Conference Publications, 2014). pp. 1-6. DOI: 10.1109/PSCC.2014.7038361.
[9] Ph. P. Barker, R.W. De Mello, "Determining the Impact of Distributed Generation on Power Systems: Part 1 - Radial Distribution Systems", 2000 IEEE PES Summer Meeting, Seattle, (WA, USA, July 11-15), pp. 222-233.

[10] Chen Y., Ma Y., Yun W., "Application of Improved Genetic Algorithm in PID Controller Parameters Optimization", Telkomnika. 2013, vol. 11, no. 3, pp. 1524-1530.

[11] Jaen-Cuellar A.Y., Romero-Troncoso R. de J., MoralesVelazquez L., Osornio-Rios R.A., "PID-Controller Tuning Optimization with Genetic Algorithms in Servo Systems", International Journal of Advanced Robotic Systems. 2013, vol. 10, pp. 324-337. DOI: $10.5772 / 56697$.

[12] Yu.N. Bulatov, A.V. Kryukov, "Optimization of automatic regulator settings of the distributed generation plants on the basis of genetic algorithm", 2nd International Conference on Industrial Engineering, Applications and Manufacturing (ICIEAM). (IEEE Conference Publications. 2016), pp. 1-6. DOI: 10.1109/ICIEAM.2016.7911456.

[13] E. Adzic, Z. Ivanovic, M. Adzic, V. Katic, "Maximum Power Search in Wind Turbine Based on Fuzzy Logic Control", Acta Polytechnica Hungarica. 2009, vol. 6, no. 1, pp.131-149.

[14] N.I. Voropai, P.V. Etingov, "Two-Stage Adaptive Fuzzy PSS Application to Power Systems", Proc. of International Conference on Electrical Engineering ICEE'2001. (July 2226, Xi'an, China, 2001, vol. 1), pp. 314-318.

[15] A.N. Belyaev, S.V. Smolovik, "Design of adaptive automatic excitation regulators using neuron-fuzzy modeling", Electricity. 2002. No. 3. pp.2-9.

[16] A.V. Kryukov, S.K. Kargapol'cev, Yu.N. Bulatov, O.N. Skrypnik, B.F. Kuznetsov, "Intelligent control of the regulators adjustment of the distributed generation installation", Far East Journal of Electronics and Communications. 2017. Vol. 17. No. 5. pp. 1127-1140.

[17] G.A. Pikina, "The principle of control according to the forecast and the possibility of adjusting the regulation systems by one parameter", New in the Russian electric power industry. 2014. No.3. pp.5-13 ["Princip upravleniya po prognozu i vozmozhnost' nastrojki sistem regulirovaniya odnim parametrom", Novoe v rossijskoj ehlektroehnergetike](in Russian).

[18] Yu.N. Bulatov, A.V. Kryukov, Nguyen Van Huan, "Automatic prognostic regulators of distributed generators", 2018 
International Multi-Conference on Industrial Engineering and Modern Technologies (FarEastCon). IEEE Conference Publications. 2018 pp. 1-4. DOI: 10.1109/FarEastCon.2018.8602718

[19] Yu.N. Bulatov, A.V. Kryukov, Nguen Van Huan, Distributed generator rotor speed automatic prognostic controller, Scientific Bulletin of NSTU. 2017. Vol. 66. No.1. pp. 15-25 ["Avtoprognosticheskij regulyator chastoty vrashcheniya rotora generatora ustanovki raspredelennoj generacii", nauchnyj vestnik NGTU] (in Russian).

[20] V.V Bushuyev, N.N. Lizalek, N.L. Novikov, Dynamic properties of power supply systems. M.: Energoatomizdat, 1995. 320 p. [Dinamicheskie svojstva ehnergoob"edinenij. M: EHnergoatomizdat] (in Russian). 